\title{
Engaging Diverse Student Cohorts: Did Someone Say Completely Online?
}

\author{
C. Moore and L. Signor
}

\begin{abstract}
Student and teacher engagement is an ongoing issue in online learning environments. Specifically demonstration and assessment of evidenced generic skill development of students is problematic. Most practitioners rely on basic tools for facilitating online such as discussion boards and chat rooms. This paper builds on the latter method and is presented in an illustrative case study analysis. The case is of a nationally recognised undergraduate online program which provides educational practitioners with tangible examples illustrating the implementation of pedagogical concepts and theories for online teaching.
\end{abstract}

Index Terms-Diversity, generic skills, higher education, online learning, student-centred discussion.

\section{INTRODUCTION}

Using a case study approach, this paper presents a nationally recognized program [1] and builds on recent publications co-authored by the writers [2], [3]. The papers included brief discussions on their innovation to an asynchronous communication approach adopted and adapted from Wright and Schoop's face-to-face "student-centred discussion model" (SCD) [4]. The innovation was in the context of engaging diverse student cohorts in a fully online undergraduate program.

This paper expands on these prior papers and discusses the adopted elements for synchronous (real-time) online student-centered discussion. The discussion is grounded in pedagogical theory and supported with tangible examples developed by the authors and implemented within several units of study within the case.

\section{BACKGROUND}

Adaption of [4]"s model for online collaboration was undertaken in cohesion with our University's strategic requirement for evidenced-based student learning outcomes, that is, the attainment of the following generic skills:

- Teamwork and communication skills;

- Analysis skills; and

- Problem-solving skills

Adhering to the University's learning and teaching strategic requirements for student evidenced learning outcomes, as educators, the emergent challenges for us were the pedagogical, instructional and curriculum design concepts for fully online learning. For example: how to

Manuscript received October 9, 2013; revised December 19, 2013.

The authors are with Information Systems with Swinburne University of Technology, Melbourne, Australia (e-mail: cmoore@swin.edu.au, 1signor@swin.edu.au). encourage our students to develop theoretical understandings of their discipline within a real world learning environment while validating their attainment of the generic skills.

The above generic skills form several of the primary objectives for each of the units of study within the case study and are in addition to the discipline specific learning requirements of each unit. Conceptually we faced a complex learning and teaching environment. For example, we have observed over many years of teaching via discussion threads that there is an unnatural "lag" in communication between students and their peers in these forums; hardly conducive to a team environment. Along with this was the challenge of meeting the University's requirements. As education practitioners and in line with our own discipline's underlying philosophy of systems and pragmatic solution design i.e. Information Technology; we looked for systematic and evidenced-based strategies for engaging diverse student cohorts in real-time online. Further, the opportunity to incorporate real-time authenticity into our online collaborative based activities for students was very exciting in addition to being very important for student engagement [5].

\section{Evolving Pedagogical Practice Drawing on the CONTEMPORARY LITERATURE}

To afford student achievement of the generic skills noted above, we purposely and proactively informed our praxis with both constructivist and social constructivist pedagogical theories [2] as described by [6]. As a strategy this provided us with a theoretical foundation for further development of online pedagogical practice within the case.

The rationale behind supporting a constructivist approach as part of the pedagogy was to acknowledge and facilitate a diverse group of students in their attainment of generic skills through real life scenarios. For example, we drew on [7]'s opinion: "Constructivist models assume that the main objective of teachers should be to support learners in gaining experiences rather than aiming to transfer "knowledge objects" from the teacher to the learner".

Findings by [8] provided support for our rationale for the integration of social constructivist theory for online education and evidence-based learning outcomes. This was primarily through their discussion targeting "assessment for learning" "through social interactions".

The extant literature has many examples of quantitative evaluations based on the usage and uptake of real-time sessions by students. Indeed, there are many articles which focus on the merits of providing students with online collaborative sessions for example [9], [10]. In contrast there are several papers that detail educators' experiences on the short comings in the online learning environment i.e. lack of 
student engagement through text-based environments [11]-[14] and best uses of virtual classrooms [15]. What appears to be absent in the literature is the focus on approaches and techniques for engaging students from diverse backgrounds within an online learning environment.

As part of the student engagement strategy developed and implemented within the case, we provided active learning opportunities for students as described in the seminal work of Meyers and Jones [16]. In addition, to assist in alleviating student and teacher isolation often experienced in the online environment [17], socially orientated activities by informally facilitating communities of practice ([18]-[21]) had been introduced. For example: asynchronous online meet and greet and "make the first move strategy" [3].

Coupled with the previously developed active learning opportunities [3], in 2010 we began to actively and overtly link the use of case studies as a tool for learning, together with the more traditional learning materials (that is: lectures and notes, learning exercises supported with asynchronous discussion activities). This case study approach to learning presents real-world scenarios which students critique and analyze in order to make informed recommendations. The approach was enabled by moving more purposefully to synchronous technologies such as simple text based chat rooms and to a lesser extent, experimental dynamic environments such as "secondlife". Within the available literature at this time, [17] propounded that the use of case studies actively engaged the learner within an asynchronous environment; a finding we felt could be mirrored in a synchronous environment as well to support the evidencing of student development of generic skills, i.e. analysis and problem solving.

Adopting and encapsulating both [10]'s discussion and [16]'s active learning findings, we adapted current active learning techniques within the case by driving the use of case studies as a key component of the pedagogy. This was achieved in part by utilizing several of [4]'s SCD elements, thus evolving online SCD for our context, i.e. including synchronous real-time activities as shown in Table I and explained in the next section. It is noted that similar research to align SCD elements to a predominantly asynchronous online environment was undertaken in parallel but not in cohesion with the case study presented in this paper by [22].

The case's Online SCD saw specific protocols developed and implemented (through action research methods) for educators in the use of chat rooms. Chat rooms were chosen as the primary vehicle to encourage exploration by students mainly due to ease of access via the University's Learning Management System (LMS) and to a lesser extent the lack of funding and support for the use of other tools at that time. As such several protocols, presented as artifacts, emerged cohesively from our praxis and scholarship that have been employed for online facilitation across broad discipline areas within the University. For example: Psychology, Marketing, and Tourism Management.

\section{ARTIFACTS}

This section provides illustration of three artifacts that formed part of University wide staff development on blended and online delivery during 2007-2012. The adoption and adaption of the SCD model [4] from face-to-face to fully online delivery is shown in Table I. Table II illustrates the real-time tutorial guidelines (developed for students and educators to support the development of communication skills by students. These guidelines were implemented across several discipline areas and faculties. Table III shows an example of real-time online SCD in action is provided to demonstrate evidence of student attainment of generic skills.

TABLE I: COMPARISON OF FACE-TO-FACE WITH ONLINE ENVIRONMENTS UTILIZING ELEMENTS OF THE WRIGHT AND SCHOOP [4] SCD MODEL

\begin{tabular}{|c|c|}
\hline $\begin{array}{l}\text { *Wright \& Schoop } \\
\text { Student-Centred Discussion Model } \\
\text { Face-to-face environment }\end{array}$ & $\begin{array}{l}\text { *Information Systems program } \\
\text { Adoption/Adaption/Innovation } \\
\text { Fully online environment }\end{array}$ \\
\hline $\begin{array}{l}\text { *Welcome message with every student's name on it } \\
\text { posted on the door of the class room }\end{array}$ & $\begin{array}{l}\text { *"Make the first move" strategy online } \\
\text { - post up a welcome message for students } \\
\text { - respond in kind to students as they post }\end{array}$ \\
\hline $\begin{array}{l}\text { *Students are provided with a sticky label for their } \\
\text { name to wear during class }\end{array}$ & $\begin{array}{l}\text { *Student discussion threads have the title of the thread altered to include the student"s } \\
\text { name in the title response for easy identification and personalisation }\end{array}$ \\
\hline $\begin{array}{l}\text { Setting an agenda detailing time allowances for tutorial } \\
\text { activities }\end{array}$ & $\begin{array}{l}\text { For synchronous (real-time) classes: } \\
\text { Setting an agenda with estimated time allocations for tutorial activities to be undertaken } \\
\text { in during the synchronous chats. } \\
\text { Allowing for students late to the session to "know where the class is up to" without } \\
\text { interrupting with "what are we up to?". } \\
\text { This affords a transcript that is reasonably clear of unrelated conversation in the middle } \\
\text { of class discussions and becomes a useful document for students and educators after class. }\end{array}$ \\
\hline $\begin{array}{l}\text { For class discussions directing students by giving them } \\
\text { time constraints for discussion of questions within small } \\
\text { groups }\end{array}$ & $\begin{array}{l}\text { For synchronous chats/class discussions directing students by giving them time } \\
\text { constraints for discussion of questions by the presenting cohort - see artefact two }\end{array}$ \\
\hline $\begin{array}{l}\text { Guidelines for participating in discussions within the } \\
\text { class and small groups }\end{array}$ & $\begin{array}{l}\text { For synchronous chats/class discussions, addressing student and educator fears and } \\
\text { expectations in a real-time text based interaction. } \\
\text { Guidelines for participating in synchronous chats - see artefact three }\end{array}$ \\
\hline
\end{tabular}

(* Table elements reproduced from Moore and Signor (2013)) [3]. 
TABLE II: SYNCHRONOUS TUTORIAL GUIDELINES FOR STUDENTS AND EDUCATORS (@ C. MOORE)

\begin{abstract}
Guidelines
The nature of a chat room makes it very difficult to manage and participate in at times and so we need to formulate some guidelines to help the online tutorial run smoothly. Over the years I have noted a number of problems that occur from my end as facilitator and from your end as participant. The following describes possible problematic scenarios and suggested solutions to help overcome them. (If you have any suggestions please let me know. :)):

A. I'm Late to the Chat Room for the Tutorial

Please don't say HELLO straight away if you are late, we are all happy to see you there, but often an entry in the middle of someone's conversation can be off putting and makes the transcript difficult to read. As facilitator, I will give you the cue for saying hello (if you are late) by saying WELCOME and your
\end{abstract} name at the first opportunity.

B. Who Responds First?

As facilitator I will ask you by name to offer your ideas or thoughts on a question. IF you cannot answer the question then type: PASS or if you want to think about the question a bit longer type: PASS LATER. I will come back to you. This way the chat room does not get hit with ten to fifteen responses at once which is when we cannot keep up with them. If you are just dying to add your bit - which I know we all do at times, you will get your turn! :- I know how you all love to discuss things. You can "raise your hand" after some-one has finished their contribution to the discussion by typing HAND and I will know to wait for your input.

C. I can't Type very Fast

I am well aware that not all of us can type very fast - in a chat room we all feel we need to type as quickly as possible. If you are happy to respond to the question straight away type in YES and then "enter" it onto the chat room and the class and I will know to wait - however when answering a question with a lengthy response sometimes it is good to type half a sentence "enter" it onto the chat board and then add your remaining text. So we know this is happening, end your first entry with ... and we all will be aware that there is more to come and we will wait.

D. When Is the Right Time to Ask Questions about Particular Things?

I include an AGENDA for each online tutorial with a rough outline of timelines - if you arrive late and have a burning question about something that happened earlier in the online tutorial, please wait to near the end of class for the "any other questions" time and I am happy to answer you.

E. Can I View the Transcript?

Transcript for your tutorials will be available immediately from the chat room web page (i.e. just before you enter the chat room).

TABLE III: TEACHING EXAMPLE, FACILITATING ONLINE REAL-TIME DISCUSSION (@ C. MOORE)

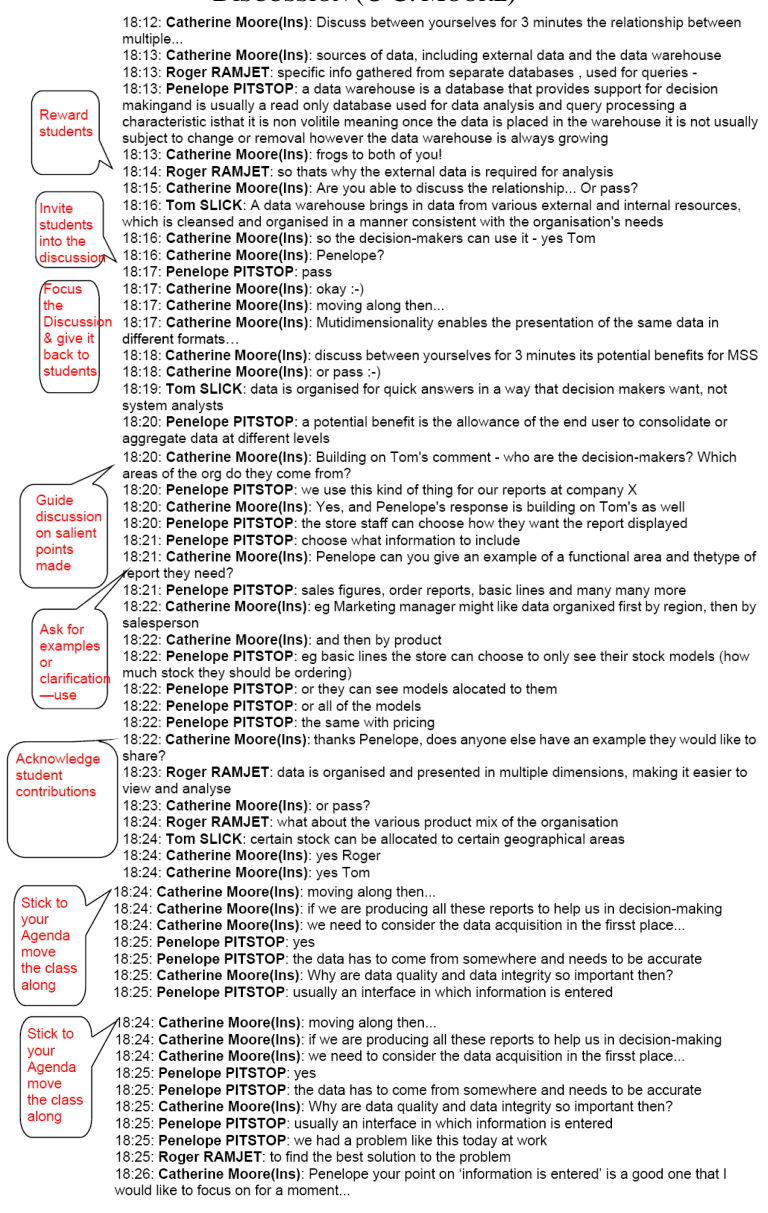

As a proof of concept a de-identified real-time online chat room transcript is presented (please see Table III). The transcript provides a window into the power of informing pedagogy using models and theory to transcend delivery modes. There are several examples within the transcript that demonstrate how the educator moves students on, i.e. "sticking to the agenda," using student's names (please see Table I), weaving discussion and building ideas and questions from students. The educator actively uses the guidelines (please see Table II) in their facilitation of the real-time chat thus creating an environment where students feel confident enough to share examples from their own work place, i.e. facilitating the incorporation of authenticity to the learning [5].

\section{LIMITATIONS}

There is a focus within the contemporary literature on engaging online students in respect of addressing observed high attrition rates within courses and programs [23]. Student attrition rates are very important to learning institutions as they are often associated with quality learning outcomes amongst other institutional realities such as funding issues and student perceptions over quality. In a recently published literature review [24], some twenty robust research studies focusing on online student attrition rates were reported on with a general finding that a student's level of persistency (measured by specific factors) influenced their continuation in online programs. Although this paper does not focus on attrition rates, it is acknowledged that student engagement techniques may have a strong relationship with student retention strategies.

Another lens prevalent within the "engaging online students literature" is that of student emotional intelligence and their ability to engage or have social presence in online settings, especially around addressing isolation ([17], [19]-[21]). Again, while this is an important area of continual investigation, it is outside the scope of this study. However, it is worthwhile noting that a common theme in the literature was on the importance of student emotional intelligence. This was particularly evident for informing the use of communication tools in predominantly text based online learning environments ([25]-[27]). 


\section{CONCLUSION}

The case reviewed and analysed in this paper is an Australian university open access online undergraduate bachelor program, nationally recognised for its inclusive online pedagogy [1]. The study revealed several generalisations manifest in artifacts that have been transferred across several undergraduate disciplines and online programs at our University. Using sound pedagogical principles of constructivism and social-constructivism, practitioners engaged diverse student cohorts in real-time collaborative sessions.

Within the case, we found through general observation that the enhanced pedagogical approach of Online SCD, as facilitated through a synchronous environment, afforded students and educators the opportunity for real-time demonstration and assessment of evidenced generic skill development. The Online SCD collaborative environment was so successful within the case that student sourced work scenarios were able to be integrated into active case study discussions (de-identified) and assessments [2] facilitating authentic learning opportunities online [5]. The integration of student sourced work scenarios now forms the basis for future research within the context of engaging diverse students in an online learning environment.

\section{REFERENCES}

[1] ALTC program awards. (2010). Flexible learning and teaching: Open access undergraduate information systems program-inclusive online pedagogy. Australian Learning \& Teaching Council (ALTC). [Online] Available:

http://www.altc.edu.au/award-enhance-learning-recipient-2010-6

[2] L. Signor and C. Moore, "Working with student diversity in an online program," in Proc. the International Conference on eLearning Futures, Auckland, pp. 31-37.

[3] C. Moore and L. Signor, "Student diversity in an online program: a case study approach illustrating evolving learning design for inclusivity," in Proc. International Conference on Higher Education ICHE, pp. 2750-2754, issue 78, Paris, France: WASET Press, 2013.

[4] D. Wright and L. Schoop, Implementing quality discussions through student-centred discussions, USA: Penn State University, 2003.

[5] H. Beetham, "An approach to learning activity design," in H. Beetham, and R. Sharpe, Eds., Rethinking Pedagogy for a Digital Age, Oxford: Routledge Falmer, 2007, pp. 26-40.

[6] C. Beck and C. M. Kosnick, Innovations in teacher education: A social constructivist approach, Albany: State University of New York Press, 2006.

[7] S. Hrastinski, "A theory of online learning as online participation," Computers \& Education International Journal, London: Elseveir Ltd, vol. 52, issue 1, pp. 78-82, 2009.

[8] K. Campbell and S. E. Gibson, "The evolution of assessment in distance education," in T. Evans, M. Haughey and D. Murphy, Eds., International handbook of distance education, Oxford: Elsevier, 2008, pp. 341-365.

[9] M. Kruger, "Students" changing perceptions on the impact of the online learning environment: what about good teaching practice?" in Proc. the International Conference on e-Learning (ICEL), Penang, Malaysia, 2010, pp.189-196.

[10] K. Rollag, "Teaching business cases online through discussion boards: Strategies and best practices," Journal of Management Education, vol. 34, pp. 499-526, 2010.

[11] R. B. Barr and J. Tagg, "From teaching to learning - a new paradigm for undergraduate education," in Proc. ASCILITE, Melbourne, 2008.

[12] S. Rowe and A. Ellis, "Can one size fit all? Using web-based audiographics to support more flexible delivery and learning," Hello! Where are you in the landscape of education technology? Melbourne, 2008.

[13] N. Harris and M. Sandor, "Developing online discussion forums as student centred peer e-Learning environments," ICT: Providing choices for learners and learning, Singapore 2007.

[14] N. Z. Zacharis, "Fostering students" participation in online environments: focus on interaction, communication and problem solving," Journal of College Teaching \& Learning, vol. 6, issue 2, pp. 10-13, 2009

[15] R. Tremblay, "'Best practices' and collaborative software in online teaching," International Review of Research in Open and Distance Learning, vol.7, no. 1, pp. 1-5, June, 2006

[16] C. Meyers and T. B. Jones, Promoting active learning strategies for the college classroom, USA: Jossey-Bass Publisher, 1993.

[17] R. Berenson, G. Boyles, and A. Weaver, "Emotional Intelligence as a predictor for success in online learning," International Review of Research in Open and Distance Learning, vol. 9, no. 2, pp. 1-17, 2008

[18] L. S. Vygotsky, "Mind in society: the development of higher psychological processes," Cambridge, Harvard University Press, 1978

[19] E. Wenger, Communities of practice: learning, meaning and identity, Cambridge: Cambridge University Press, 1998.

[20] E. Stacey, K. Barty, and P. Smith, "Designing for online communities of learning," in Proc. the $22^{\text {nd }}$ Australasian Society for Computers in Learning in Tertiary Education Conference, Brisbane, 2005, pp. 629-635

[21] P. Leong, "Role of social presence and cognitive absorption in online learning environments," Distance Education, vol. 32, no. 1, pp. 5-28, 2011.

[22] R. C. Dixon, K. C. Dixon, and M. Axmann, "Online student centred discussion: creating a collaborative learning environment," Hello! Where are are you in the landscape of educational technology? Melbourne, pp. 256-264, 2008.

[23] L. M. Angelino, F. K. Williams, and D. Natvig, "Strategies to engage online students and reduce attrition rates," The Journal of Educators Online, vol. 4, no. 2, July, 2007, pp. 1-14

[24] C. Hart, "Factors associated with student persistence in an online program of study: a review of the literature," Journal of Interactive Online Learning, vol. 11, no. 1, Spring 2012, pp. 19-42.

[25] G. S. Lewis, "I would have had more success if...: student reflections on their performance in online and blended courses," American Journal of Business Education, vol. 3, no. 11, pp. 13-21, 2010.

[26] E. Lavolette, M. A. Venable, E. Gose, and E. Huang, "Comparing synchronous virtual classrooms: student, instructor and course designer perspectives," Tech Trends: Linking Research \& Practice to Improve Learning, September 2010, vol. 54, issue 5, pp. 54-61, 2010.

[27] S. T. Hibbard, A. P. Bellara, and P. Vermette, "Evaluating the use of online discussion boards for pre-service teacher learning," The International Journal of Learning, vol. 17, no. 6, 2010, pp. 175-187, 2010 .

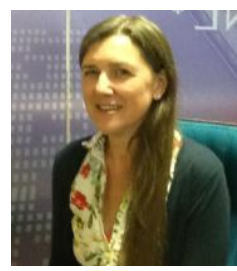

C. Moore received BAppSci (IT) (SUT) Australia in 2000, GCTeach (HED) (SUT) Australia in 2006 PCTeachPrac (SUT) Australia in 2008, and PGC ODE (OU) United Kingdom in 2011, and MPET (Deakin) Australia in 2013.

She has spent several years credentialing in both Higher Education learning and teaching and Professional learning. Fields of study include

information systems, multi-model delivery of higher education, student diversity and online education. Recent endeavours include research into student attrition in online courses.

Currently, after an extended time leading and managing the academic arm of Swinburne"s online education programs (2007-2012), she has re-engaged with teaching both undergraduate and postgraduate students within the information systems discipline at Swinburne"s main campus in Melbourne, Australia.

Ms. Catherine Moore is the recipient of two national teaching and learning awards from the Australian Office of Learning Teaching (OLT formerly ALTC): National Citation 2008 \& National Program Award 2010.

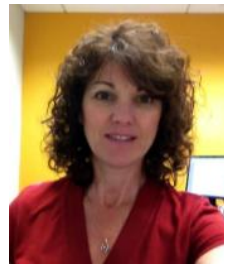

L. Signor received GCBIT (SUT) Australia in 1992 , GDBIT SUT) Australia in 1994, GDEdStu (Latrobe) Australia in 2002, and Med (Latrobe) Australia in 2009. Her career as an Academic began in 1996 with Swinburne University of Technology. She has extensive experience delivering Information Systems units in both face-to-face and online environments at undergraduate and postgraduate levels. Her leadership role at Swinburne University have included Discipline Leader, Program Coordinator and Academic Training Manager for online and blended modes of delivery. Her research interests are focused on andragogy with emphasis on multi-model delivery, student diversity and online education.

Ms. Luisa Signor is the recipient of two national teaching and learning awards from the Australian Office of Learning Teaching (OLT formerly ALTC): National Citation 2008 \& National Program Award 2010. 